\title{
A CONDIÇÃO MOURA
}

\author{
RAUL ANTELO rememora sua trajetória acadêmica para \\ discutir as dificuldades na vida de um pesquisador
}

Um momento na carreira em que tenha me equivocado... Não posso menos do que evocar a própria passagem pela Universidade. Minha formação de base se deu na tradição filológica hispânica, primeiramente, nos estudos de bacharelado, onde já se impunha forte erudição. Não tinha mais de quinze anos quando, em 1965, ouvi uma palestra, "Simples achegas no sétimo centenário de Dante", feita por Ángel J. Battistessa, cujos gestos de grand seigneur, bastante afetado, aliás, imitava em sala, despertando o riso dos colegas. Mas, para além da chacota, a erudição era, então, um valor. Abruptamente, numa noite de 1966, passei, no entanto, do exemplum pedagógico à laus mística. Deixei a sondagem dos abismos de cobiça e luxúria, no paródico e carnavalizado Libro del buen amor, guiado pelo mestre Andrés Avellaneda, daí em diante refugiado no campus universitário de Gainesville e, sem delongas, acompanhados dessa vez por uma professora de família patrícia, adentramos nos Milagros de Nuestra Señora de Gonzalo de Berceo. Súbita passagem. Decididamente, algo estava errado. Era a Revolução Argentina.

Já na faculdade, esse pendor pela erudição só cresceu e, nesse sentido, é muito esclarecedor meu primeiro "erro crítico". Prestava as provas finais da disciplina Literatura Espanhola II, cujo conteúdo girava sempre sobre o Século de Ouro. Daquela vez, tinha sido um semestre inteiro para ler o Quixote, sua exaustiva bibliografia crítica e, em particular, alguns textos preparatórios, como o Amadís de Gaula e outros que a história não conservou. Tratava-se de uma orientação talhada pelo Instituto de Filologia da Universidade de Buenos Aires, marcado desde os anos 20 por Américo Castro, esse filólogo "brasileiro", uma vez que nascera no Rio de Janeiro. Como se sabe, o Instituto teve, em suas origens, um debate muito acalorado entre os partidários da obediência irrestrita a Menéndez Pidal ou Tomás Navarro Tomás, que pretendiam ter um 
Instituto espanhol em Buenos Aires, e os jovens e não tão jovens continuadores de Amado Alonso, cujo contato com variantes locais os conduzira a encarar a tarefa dos estudos pan-hispânicos a partir de Buenos Aires. Por isso, para minha geração, em pleno clima 68, de forte impugnação dos cânones, as aulas de Frida Weber de Kurlat ou Celina Sabor de Cortazar, por exemplo, eram, até certo ponto, inadmissíveis, porque, em mais de vinte conferências de duas horas cada, jamais incluíram, para o nosso espanto, o Pierre Menard do Borges na leitura hiper-minuciosa que elas propunham do Quixote, atraídas que estavam pela tradição canônica medieval hispânica, de que o monumental livro de Curtius era então emblema.

Embora precedido por avaliações muito boas, no exame final da disciplina, feito, como de praxe, diante de banca examinadora integrada pelas duas titulares e mais três ou quatro professores assistentes, fui convidado a desenvolver um tópico para, a seguir, me examinarem sobre mais três ou quatro temas aleatórios. A certa altura, a professora Weber de Kurlat me questiona acerca de Menosprecio de corte y alabanza de aldea de frei Antônio de Guevara, bispo de Mondonhedo, que, em 1539, publica um volume, "dirigido al muy alto y poderoso Señor Rey de Portugal, don Juan, tercero de este nombre”. Estávamos em casa. Se Guevara era bispo em Mondonhedo, um outro antepassado meu, pela linhagem dos Riveiro, fora também autoridade eclesiástica e, morando em Negreira, desempenhara-se mais perto da civilização, em Santiago de Compostela. No alto da nossa arrogância e insolência adolescentes só podíamos nos identificar com a questão do desprezo em relação ao ancien regime universitário que, intuíamos, estava com os dias contados. E nossa atenção resgatava esses valores emergentes logo no incipit do tedioso tratado:

\footnotetext{
Después que este muy ilustre príncipe Filipo venció a los atenienses, aconteció que, como una noche estuviese cenando y se moviese plática entre él y los filósofos que allí se hallaban sobre cuál era la mayor cosa que había en el mundo, dijo un filósofo: «La mayor cosa que hay en el mundo es a mi ver el agua, pues vemos que hay más de ella sola que de todas las otras cosas juntas.» Otro filósofo dijo que la mayor cosa del mundo era el Sol, pues sólo su resplandor abasta a alumbrar al
} 
cielo, y al aire, y a la tierra, y al agua. Otro filósofo dijo que la mayor cosa del mundo era el gran monte Olimpo, la cumbre del cual sobrepujaba al aire y que de lo alto de él se descubría el mundo todo. Otro filósofo dijo que la mayor cosa del mundo era el muy famoso gigante Atlas, sobre la sepultura del cual estaba fundado el espantable monte Etna. Otro filósofo dijo que la mayor cosa del mundo era el gran poeta Homero, el cual fue en la vida tan famoso y en la muerte $\tan$ llorado, que pelearon entre sí siete muy grandes pueblos sobre quién guardaría sus huesos. El postrero y más sabio filósofo dijo: «Nil aliud in humanis rebus est magnum nisi animus magna despiciens.» Quiso por estas palabras decir: «Ninguna cosa con verdad se puede en este mundo llamar grande si no es el corazón que desprecia cosas grandes.» ¡Oh!, alta y muy alta sentencia, digna por cierto de notar y aun de a la memoria encomendar, pues por ella se nos da a entender que las riquezas y grandezas de esta vida es muy más digno y de mayor gloria el que tiene ánimo para menospreciarlas que no el que tiene ardid para ganarlas.

Aliás, a essas alturas aprendera já na História da literatura ocidental de Otto Maria Carpeaux (comprada em Buenos Aires, naquele mesmo ano, de Christóvam de Camargo, o antigo camarada de Mário de Andrade) e mais até, compreendera a congenialidade estrutural, não mediada por influência direta, entre Guevara e John Lyly, um dos metaphysical poets. Mas Weber de Kurlat, pautada por seu mestre, Américo Castro, que estudara Guevara em Hacia Cervantes, ou tocada por Raymond FoulchéDelbosc, esse erudito conterrâneo de Menard, ou mesmo pela edição de Martínez de Burgos, apenas se interessava pelo contexto: o príncipe estava jantando quando este debate começa, e ela só queria saber, portanto, das metáforas gastronômicas. Citei algumas. Não convenci. Ela só me disse: "O senhor está citando exemplos dados por María Rosa Lida de Malkiel em seu artigo "Frei Antonio de Guevara. Idade Média e Século de Ouro espanhol”, publicado na Revista de Filologia Hispânica em 1945. Cite cinco metáforas que Maria Rosa Lida não cite”. Só consegui lembrar de três e o veredito foi inapelável: "O senhor não está preparado". Reprovei. Muito mais tarde, desempenhando-me como professor na Duke University, vim estreitar laços com Alberto Moreiras quem, muitos anos depois de minha então humilhante reprovação, 
dedicaria um ensaio a outro livro de Guevara, El Arte de marear, em que Moreiras via despontar a autonomização do texto literário. Voilà. Era isso o que já nos incomodava em 1971. A autonomia transformada em reivindicação técnica apolítica, quando ela se exercia como privilégio da erudição estéril. Não nos atraía aos jovens estudantes daquela época a matéria e forma em poesia, título do canônico texto de Amado Alonso, lido logo em meu primeiro curso no secundário, mas nos fascinavam os meandros da potência do pensamento, tal como elaborada já pelos autores da tradição medieval e da Renascença. Não nos preocupava, em poucas palavras, o auctor, mas éramos atentos, porém, ao scriptor. Talvez isso explique um segundo "erro", a leitura radicalmente ideológica com que abordei o intertexto latino-americano na biblioteca de Mário de Andrade, cujos volumes comecei a manusear em 1973. Obviamente, Emir Rodriguez Monegal, um historiador da literatura que, a seu modo mais atualizado, não realizara uma crítica dos pressupostos historicistas da autonomia, e não estava, de fato, muito além da filologia histórica em que eu mesmo me formara, só podia considerar "errada” minha leitura da vanguarda, que ele simplesmente tachava de dogmática e bisonha. Cum grano salis, Monegal absorvia, por aquela época, a versão Yale do desconstrucionismo. Tempo depois, no entanto, eu mesmo viria a compreender que, sem uma leitura em plus d'une langue, não poderia ter acesso a uma autêntica leitura política e derraparia constantemente na interpretação judicativa e ideológica.

Mais ou menos na mesma época, em Infância e história, Giorgio Agamben definia a filologia como essa progressiva observação da particularidade de um texto que, magicamente, fixa a ele o seu leitor. Mais do que me interessar pela estabilidade das leituras, é evidente que me interessava o movimento delas e, nesse sentido, era a magia que me atraía em meu trabalho. Entretanto, o último Agamben, o de Signatura rerum, por exemplo, explicitaria, porém, o enfoque retificado, quando alerta que a atenção dispensada aos documentos do passado não pode nunca limitar-se à filologia histórica. A arché que eles manifestam não é nunca uma origem fixa no tempo, mas um valor que, no cruzamento ambivalente de diacronia e sincronia, torna inteligível tanto o presente do pesquisador quanto o passado do seu objeto. Nos lemos, lendo. É isso que define a perícia crítica ao examinarmos os documentos de um 
arquivo. Como disse recentemente Jerome McGann,

\begin{abstract}
the elementary act of preservation marks the value of these materials when their normal values, whether for use or exchange, have been lost. More crucially, philological attention continues to be paid even as we recognize that the value of what we preserve may never again be realized. "Never again" is crucial. For the philologian, materials are preserved because their simple existence testifies that they once had value, though what that was we can never know completely or even, perhaps, at all. If our current interests supply them with certain kinds of value, these are but Derridean supplements added for ourselves. For the philologian, the dead and their trace memories are precious and honorable as such.[1]
\end{abstract}

Em Chacais e árabes, Franz Kafka narra o desafio imposto ao narrador para acabar com a disputa que dividia o mundo em dois. Nossos antepassados descreveram aquele que irá fazê-lo, exatamente assim como você é - disse-lhe um sujeito que chega em caravana - porque precisamos de paz com os árabes, precisamos de um ar mais respirável. Não ouvir, por exemplo, nenhum grito de lamúria de um carneiro que o árabe esfaqueie. Limpeza, só limpeza, era a palavra de ordem, e para tanto, lhe entregam ao visitante uma tesoura que, quase um século depois, ainda não acabou de completar sua tarefa[2]. Em um dos episódios intercalados do Quixote, o do curioso impertinente (esses episódios que devíamos citar cronológicamente e sem hesitar), Anselmo, o marido ciumento, encomenda a Lotário perseguir a sua mulher para descobrir a verdade: houve traição? A certa altura, porém, Lotário, irritado, diz ao amigo que sua atitude de desconfiança e dúvida, de incerteza diante dos fatos, de absoluta descrença com relação ao positivismo, lhe relembra

uma espécie de arremedo dos mouros: aos mouros não se pode mostrar o erro da sua seita com as citações da Escritura, nem com razões que assentem em especulação do entendimento, ou se fundem em artigos de fé; não admitem senão exemplos palpáveis, fáceis, inteligíveis, demonstrativos, indubitáveis, como demonstrações matemáticas das que se não podem negar, como quando se diz: "Se de 
duas partes iguais tiramos partes iguais, as restantes serão também iguais". E quando nem isto mesmo entendem de palavra; como de feito o não entendem, há de se lhes mostrar com as mãos, e meter-selhes pelos olhos; e assim mesmo ninguém consegue convencê-los das verdades da nossa santa religião. No mesmo aperto me vejo eu contigo, porque esse teu desejo é tão sem caminho, e tão fora de toda a racionalidade, que me parece será tempo perdido o que se gastar para te convencer da tua simpleza, que por enquanto lhe não quero dar outro nome; e quase que estou em deixar-te lá com o teu desatino, para castigo do teu mau desejo; mas vale-te a amizade que te professo; ela é que me não consente de te desamparar e em tão manifesto perigo de perdição[3].

O bom pesquisador é sempre, para si mesmo, um árabe e deve aprender de sua própria condição moura se não quiser dar à tesoura um uso abjeto.

[1] McGANN, Jerome - Philology in a new key. Critical Inquiry, Vol. 39, nº 2, inverno 2013, p. 345-346

[2] HANSSEN, Jens - Kafka and arabs. Critical Inquiry, Vol.39, nº1, outono 2012, p.167-197

[3] CERVANTES SAA VEDRA, Miguel de - Dom Quixote de la Mancha. Trad. Viscondes de Castilho e Azevedo. São Paulo, Nova Cultural, 2002, p.217

\footnotetext{
RAUL ANTELo é doutor em Letras pela FFLCH-USP e professor de literatura na UFSC. Publicou João do Rio: o dândi e a especulação (Timbre/Taurus, 1989), Algaravia: discursos de nação. (Edufsc, 1998), entre outros.
} 